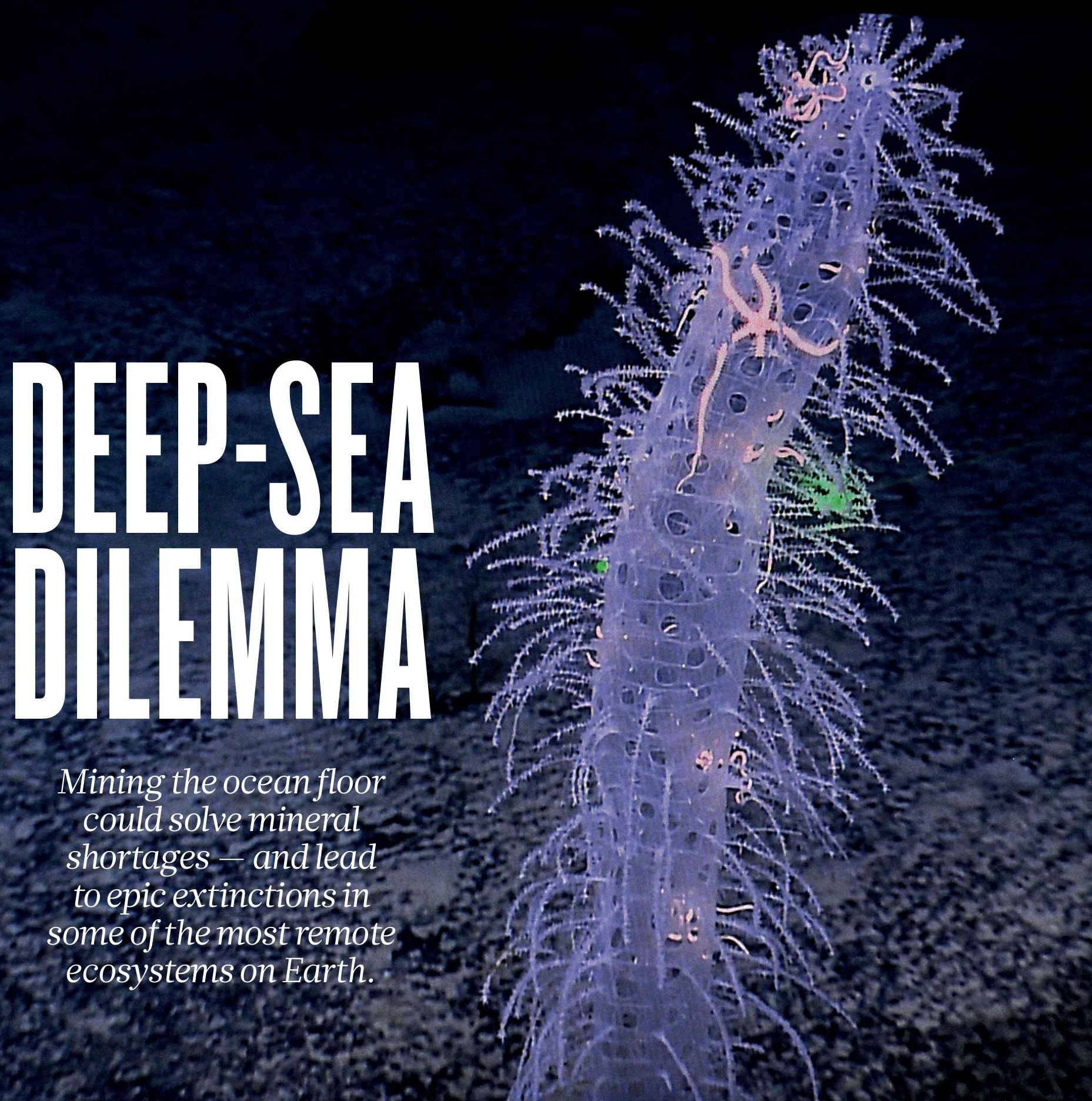

BY OLIVE HEFFERNAN n 1972, a young ecologist named Hjalmar Thiel ventured to a remote part of the Pacific Ocean known as the Clarion-Clipperton Zone (CCZ). The sea floor there boasts one of the world's largest untapped collections of rare-earth elements. Some 4,000 metres below the ocean surface, the abyssal ooze of the CCZ holds trillions of polymetallic nodules - potato-sized deposits loaded with copper, nickel, manganese and other precious ores.

Thiel was interested in the region's largely unstudied meiofauna - the tiny animals that live on and between the nodules. His travel companions - prospective miners - were more eager to harvest its riches. "We had a lot of fights," he says. On another voyage, Thiel visited the Red Sea with would-be miners who were keen to extract potentially valuable ores from the region's metal-rich muds. At one point, he cautioned them that if they went ahead with their plans and dumped their waste sediment at the sea surface, it could suffocate small swimmers such as plankton. "They were nearly ready

A ghostly sponge lives on a Pacific seamount, one of the environments targeted by contractors interested in mining the ocean floor. to drown me," Thiel recalls of his companions.

In a later confrontation, Thiel - who was at the University of Hamburg in Germany - questioned how industry planned to test the environmental impacts of sea-bed mining. He was curtly advised to do his own test. So he did, in 1989.

Thirty years on, the test that Thiel and a colleague devised is still the largest experiment ever on the potential impacts of commercial deep-sea mining. Called DISCOL, the simple trial involved raking the centre of a roughly 11-square-kilometre plot in the Pacific Ocean with an 8-metre-wide implement called a plough harrow. The 
simulated mining created a plume of disturbed sediment that rained down and buried most of the study area, smothering creatures on the sea floor. The test revealed that the impacts of sea-bed mining reached further than anyone had imagined, but it did not actually extract any rocks from the sea bed, which itself would have destroyed even more marine life.

There have been many attempts to advance DISCOL's basic approach, but none has succeeded, mostly owing to technical and financial difficulties. The most recently planned mining trial, to test a robotic nodule harvester in the CCZ this April, was called off at the last minute because of a technical failure. The trial, planned by the Belgian contractor Global Sea Mineral Resources, would have given scientists a better grasp of the impacts of sea-bed mining by using a 25-tonne tractor to plough the ocean floor.

"This was definitely a significant setback, because it was really the only opportunity to try to even start to see the interaction of these big, heavy machines with the marine environment," says Kristina Gjerde, a high-seas policy adviser with the International Union for Conservation of Nature in Cambridge, Massachusetts.

Such has been the troubled trajectory of deep-sea mining ever since eager industrialists proved, nearly a half century ago, that it was technically feasible to extract rare metals and minerals from the ocean floor. Companies and nations have often promised that they would soon start pulling valuable ores from the depths, but commercial efforts have failed to take off for a variety of reasons - notably huge up-front costs, the historically low value of deepsea ores and the lack of regulations, which have contributed to investors' wariness.

"The technology is available - it's the financial and regulatory uncertainty that has held the industry back," says Govinder Singh Chopra, founder of SeaTech in Singapore, a designer of deep-sea mining support vessels.

Now, it seems this nascent industry's time has come. A growing demand for batteries to power electric cars and to store wind and solar energy has driven up the cost of many rare-earth metals and bolstered the business case for sea-bed mining. What's more, the industry's long-awaited regulations - in the form of a mining code - are due to be finalized by 2020 , putting in place a process whereby contractors can apply for 30-year licences to mine assigned 'claim areas' in parts of the international sea bed such as the CCZ. Already, miners are exploring the potential wealth of these claim areas, but no commercial extraction will begin until the regulations are in place. Investments in this industry are now growing.

Last month, a start-up called DeepGreen in Vancouver, Canada, announced that it is raising US\$150 million to begin exploring mineral wealth in part of the Pacific Ocean - a sign of growing confidence in the industry's future.

Both scientists and conservationists, however, are worried that the creation of regulations will encourage the industry to start mining long before there is enough information on how operators can avoid causing serious environmental harm. The scarce data that exist suggest that deep-sea mining will have devastating, and potentially irreversible, impacts on marine life.

Since the DISCOL experiment was completed, scientists have returned to the site four times, most recently in 2015. The site has never recovered. In the ploughed areas, which remain as visible today as they were 30 years ago, there's been little return of characteristic animals such as sponges, soft corals and sea anemones. "The disturbance is much stronger and lasting much longer than we ever would have thought," says Thiel.

\section{THE QUIET PLACE}

The deep sea - usually defined as the realm below 200 metres - is a world of extremes. Temperatures near the sea bed in many places hover near $0^{\circ} \mathrm{C}$, there is next to no light, and pressures can exceed 1,000 bars, equivalent to having a couple of elephants standing on your big toe. But still life thrives. The deep sea contains a vast array of ecosystems that researchers have barely begun to study.

Miners have focused on three environment types to explore for potential harvesting. Abyssal plains such as the CCZ are littered with metallic nodules that form over millions of years as minerals precipitate around fish teeth, bones or other small objects. These regions are some of the quietest, most remote ecosystems on the planet, where fine sediment rains down at a rate of about one centimetre every 1,000 years. That low-energy environment is home to polychaete worms, crustaceans, sponges, sea cucumbers, starfish, brittlestars, sea urchins and various deep-sea fish, as well as countless microbial species and tiny sediment-dwelling creatures.

Another type of mineral deposit is the metal-rich crust that covers seamounts, which rise thousands of metres above the abyssal plains. These coatings are packed with high-value metals, such as cobalt, platinum and molybdenum. The seamount environment is dominated by corals, sponges and other filter feeders as well as tuna, sharks, dolphins and sea turtles.

A third form of mineral deposit that is attracting attention is massive sulfides - rich in copper, lead, zinc, gold and silver. These ores form around vents of superheated water that occur along the volcanic ridges running through ocean basins. The hydrothermal vents support creatures such as the small, blind yeti crab (Kiwa tyleri) with its characteristic blonde, furry hair, and the scaly-foot snail (Chrysomallon squamiferum), which armours its soft interior with an iron shell and is the first deep-sea animal to be declared endangered because of the threat of mining (see page 455).

For years, it was assumed that the first deep-sea environment to be mined would be hydrothermal vents in Papua New Guinea's territorial waters. Nautilus Minerals in Toronto, Canada, was pursuing that project, but financial difficulties and local opposition derailed the venture, leaving the $\mathrm{CCZ}$ as the most likely test bed for deep-sea mining. Estimates suggest that the nodules in that region contain more cobalt, manganese and nickel than the total of all known deposits on land (see 'Sunken treasure'). The CCZ stretches from Hawaii to the Baja California Peninsula, and is as wide as the contiguous United States.

Companies are steadily moving forward with plans to exploit the minerals in the CCZ. The International Seabed Authority (ISA) - a 168-member body created by the United Nations to both promote and regulate sea-bed mining - has, in the past decade, granted 29 exploration licences for contractors sponsored by national governments to explore mineral wealth at a number of deep-sea locations. Of the licences granted, 16 are for the CCZ, and these cover about $20 \%$ of the total area.

Since Thiel's first visit to the region in 1972, scientists have explored it in much more detail. Deep-sea biologist Craig Smith at the University of Hawaii in Honolulu has spent 30 years studying the communities in the CCZ, where he has collected sea cucumbers, sea urchins, soft corals, starfish, sea anemones, worms and much more. Roughly $90 \%$ of the animal species his group has collected are new to science or undescribed. Among these are rare species not found anywhere else in the deep sea. Smith thinks that, even now, scientists have sampled just $0.01 \%$ of the total area of the CCZ.

In one single UK claim area of 55,000 square kilometres, Smith and his colleagues were surprised to collect more than 1,000 animal species, which they estimate is less than half the total number living there. "And that's not counting the microbes, of which there are over 100,000 different species," says Smith. "We expect that there are thousands of species that are unique to the CCZ," he says. "I've been studying biodiversity there for decades, but we still don't know that much." Some of the species could have small ranges, so if they were to be wiped out, it would be a global extinction. 


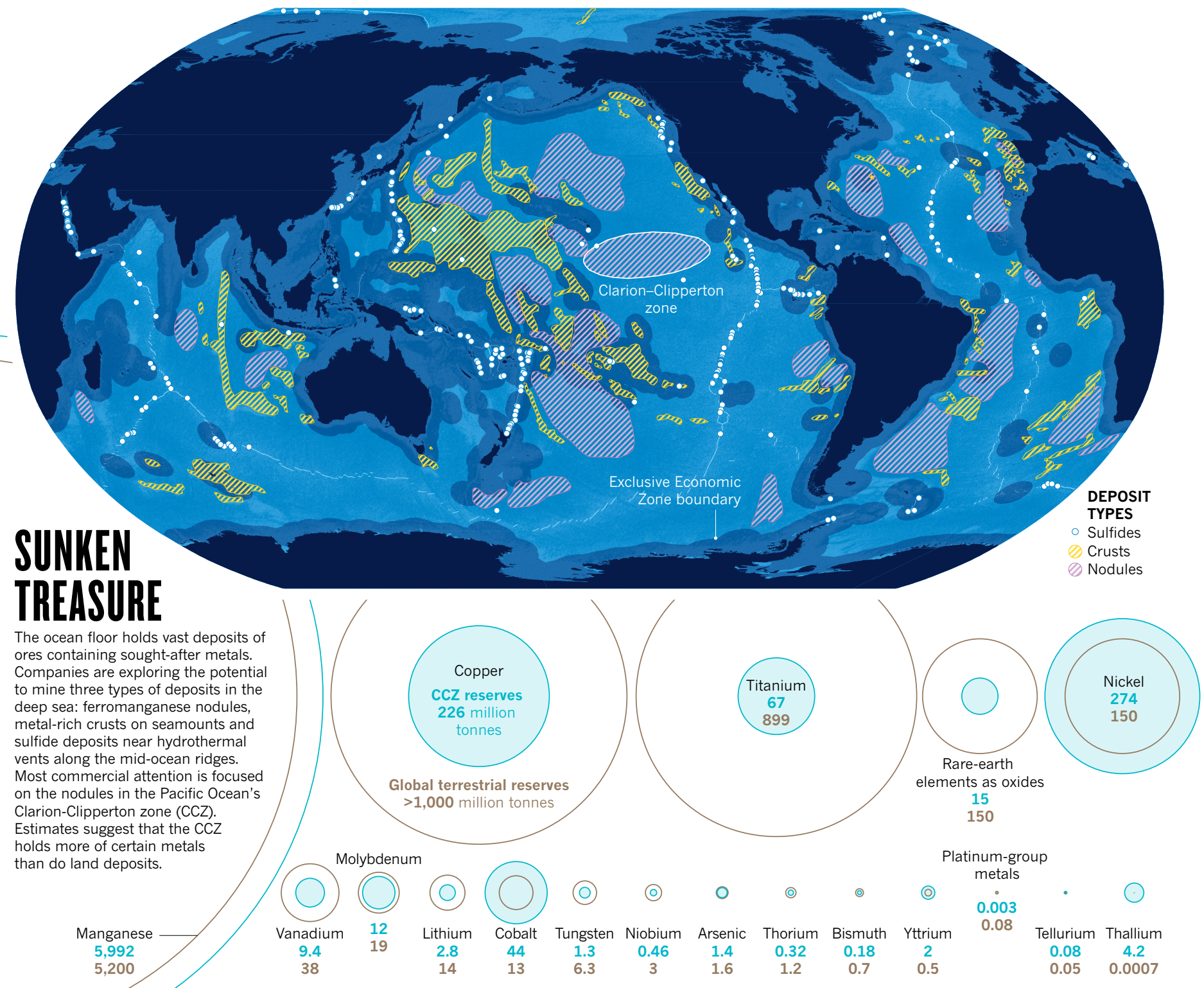

DATA GAPS

Although deep-sea mining threatens some of these species, it has also raised awareness of the biodiversity of the sea-floor environment. By law, mining contractors are required to assess what lives in their claim area, and Smith and many other deep-sea biologists conduct ecological surveys to help contractors establish this baseline. And prospective miners can carry out tests to understand how their equipment will impact the environment they are working in.

The aim of such studies is to help miners and the ISA reduce any potential harm from the industry and to develop environmental management plans. But many researchers say that the system has not worked well in practice, in part because the requirements for baseline data are weak.

The data have been confidential, but are becoming publicly available this month. "It's going to be quite telling because we'll have an insight for the first time into the quality and quantity of contractor data. My guess is that many contractors are not putting together what we would regard as a thorough baseline assessment," says Daniel Jones, a deep-sea ecologist at the National Oceanography Centre in Southampton, UK.

Another concern among researchers is that there are no requirements to test the environmental impacts of the giant mining machines before commercial extraction begins. Since 1970, only 12 small-scale tests have been done on nodule mining, most using a narrow, roughly 2.5-metre-wide instrument to disturb the sea floor. Of these, DISCOL is regarded as the most advanced, mostly because of the wider plough, the large area covered and the long time series of data. "All of these studies have flaws, and DISCOL, too, is imperfect, but it's the best we have," says Jones.

Many scientists and conservationists say that the root of some of the problems is that the ISA has dual responsibilities. When it was established by the UN in 1994, the ISA was given two mandates: to protect the international sea bed from serious harm, and to develop its resources, ensuring that their exploitation benefits humankind. (In national waters, countries can develop their own rules around sea-bed mining, but they must be at least at strict as the rules that will be adopted next year by the ISA). The "ISA is both poacher and gamekeeper", says Hannah Lily, a maritime lawyer with the Pew Charitable Trusts in London, who is not speaking on behalf of Pew.

The ISA has responded to some of these concerns. It says that "an extremely important aspect of ISA's mandate is ensuring appropriate environmental assessments and safeguards in the activities that it regulates", for instance.

It also says that "its decisions are made by consensus among the 168 countries that make up its membership, all countries having one vote". So far, the membership has approved only exploration activities.

The Belgian contractor Global Sea Mineral Resources has defended how mining contractors and the ISA are moving forward. It says that the ISA has been proactive in establishing an environmental management 
plan that includes setting aside nine areas of particular environmental interest. The intention is keep these areas - about $30 \%$ of the CCZ free of mining to protect biodiversity.

\section{SMOTHERED BY SEDIMENT}

Mining in the CCZ, if it does happen, is still almost a decade away, with Global Sea Mineral Resources aiming to open a commercial deep-sea mine by 2027 . When it does kick off, the scene at the ocean bottom will look something like this: robotic machines as large as combine harvesters will crawl along, picking up metallic nodules and sucking up the top 10 centimetres or so of soft sediment with them. Because the nodules grow so slowly, mining them will effectively remove them from the sea floor permanently, say scientists.

The nodules are an irreplaceable habitat for many of the creatures that live in the CCZ. "For most of the animals in the direct vicinity, mining will be lethal. It will wipe out most of the large animals and everything that's attached to the nodules. That's a given, I would say," says Henko de Stigter, an ocean-systems scientist at the Royal Netherlands Institute for Sea Research in Texel, whose assessment is shared by many researchers.

But the impacts of mining in the CCZ would be much broader than just killing the ecosystem around the nodules. As the collectors moved across the sea floor, they would stir up large clouds of soft sediment that would disperse, possibly for tens of thousands of kilometres, before eventually resettling. At high densities, sediment plumes can bury and smother the animals on the sea floor. Just how far the sediment will disperse remains unknown. "We're only starting to see how far the plume reaches and we're still very far from knowing what the effect will be," says de Stigter. Next month, he will test the impacts of a prototype nodule harvester in shallow Mediterranean waters.

Scientists are also carrying out laboratory and computer simulations to assess the impact of the disturbed sediment. One computermodelling study, published in January (B. Gillard et al. Elem. Sci. Anth. $7,5 ; 2019)$, found that the sediment could take up to ten times longer to resettle than is currently assumed, meaning it will probably travel farther in the water column. And some researchers say that even trace amounts of sediment stirred up by the mining operations could smother sea-floor life far away.

In the CCZ, once the nodules have been collected by a harvester, they'll be shunted up a kilometres-long tube to a large surface support vessel, which will sort out millions of nodules a day and return the waste sediment to the sea, creating yet another plume. Right now, there's little clarity on where the waste will be released, in part because returning sediments to the sea bed is costly and technically challenging. One suggestion is to reinject the plume at a depth of 1,000 metres, still thousands of metres above the sea bed. Scientists worry that this practice could harm or kill life at mid-water depths, just as Thiel feared 30 years ago.

Without more information about these deep-sea environments, researchers don't even know how to define the risks. "What is serious harm? There are some clear red lines, but there's no definitive answer to that question yet," says Gordon Paterson, one of three ecologists who sit on the ISA's Legal and Technical Commission (LTC), which is, in part, a scientific advisory body. "We understand that global extinction is serious harm and we know that interference in carbon sequestration is serious harm. Scientists know that mining will cause local extinction of species in the CCZ, but are we talking about the extinction of species across the CCZ or just in the mined area? It is complicated," he says.

\section{HOW TO START AN INDUSTRY}

Amid this dearth of data, the ISA is pushing to finish its regulations next year. Its council met this month in Kingston, Jamaica, to work through a draft of the mining code, which covers all aspects - environmental, administrative and financial - of how the industry will operate. The ISA says that it is listening to scientists and incorporating their advice as it develops the regulations. "This is the most preparation that we've ever done for any industrial activity," says Michael Lodge, the ISA's secretarygeneral, who sees the mining code as giving general guidance, with

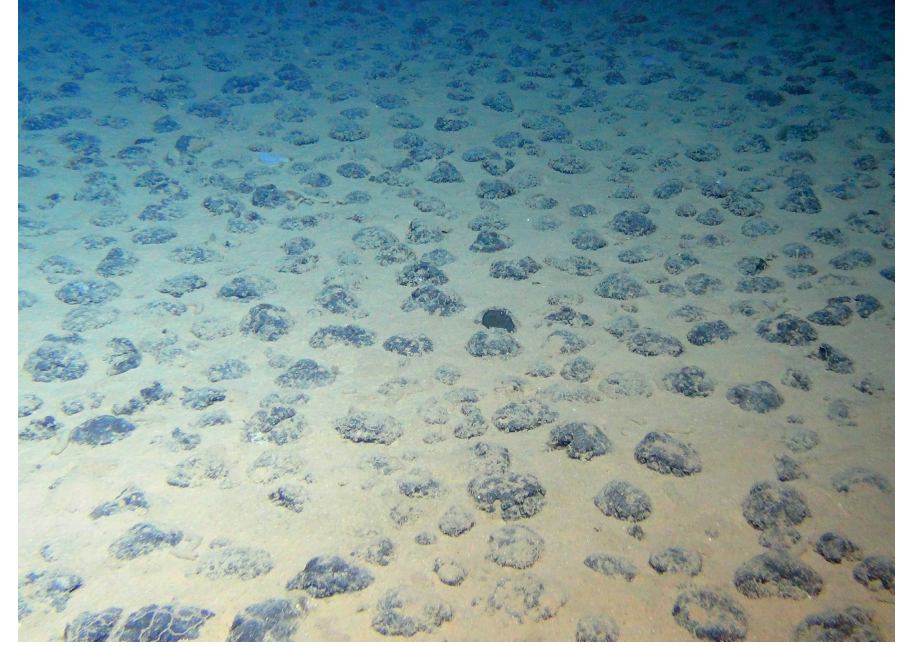

Manganese nodules cover the sea floor in the Clarion-Clipperton Zone.

room to develop more progressive standards over time.

And many scientists agree. "This is much better than we have acted in the past on oil and gas production, deforestation or disposal of nuclear waste," says Matthias Haeckel, a biogeochemist at the GEOMAR Helmholtz Centre for Ocean Research Kiel in Germany.

The ISA has been criticized by some researchers for seeking expert advice only from the three LTC ecologists. But Cindy Van Dover, a deepsea biologist at Duke University in Durham, North Carolina, says that the ISA receives a lot of free help from scientists such as herself. "There's a lot of behind-the-scenes science that's being fed into ISA," she says.

Another charge levelled at the ISA is that it is not transparent about how it makes decisions; the meetings of the organization's legal and technical commission, for example, are closed, and the summary reports lack detail, say Gjerde and Jones. In particular, many are upset that scientists aren't consulted more in the granting of exploration licences. Last year, for example, Poland was awarded the right to explore 10,000 square kilometres of the Mid-Atlantic Ridge for mining. The claim area is adjacent to the Lost City, a unique hydrothermal field that has been earmarked by the United Nations Educational, Scientific and Cultural Organization for World Heritage Site status. Both scientists and conservationists have objected to this decision. Among the critics is Gretchen Früh-Green, a biologist at the Swiss Federal Institute of Technology in Zurich, who was part of the team that discovered the Lost City in 2000.

It's also clear that many would like the industry to find a better way of judging the harm deep-sea mining might cause before commercial extraction begins. "As the inventor of DISCOL, I would say we need a better experiment," says Thiel. But contractors say it would be prohibitively expensive to carry out a full-scale mining trial.

The ISA sees an advantage in moving forward. "Once you have mining, you have monitoring, then you can develop standards and you can progressively tighten those standards once you have a feedback loop from monitoring your activity," says Lodge.

Not everyone is convinced that this wait-and-see approach will work. "If industry proceeds so far, if they invest money, they will want a certain security that they can do the mining. So monitoring the mining test will not change much," says Thiel. Jones agrees. "The regulations are quite hard to amend once they are put in place," he says. "It would require the agreement of many nations that only meet infrequently".

For the moment, the ISA has the tough job of getting its 168 member nations to even agree on the draft code, which conservationists and scientists hope will mandate industry to behave responsibly. After that, it will take several years for mining companies to raise money for their ventures and to build and test equipment. Given those constraints, there's still an opportunity for scientists to improve how they gauge the risks of harvesting minerals from the sea floor. "You can't just stick your head in the sand," says Van Dover, "and hope it will all go away." -

Olive Heffernan is a science journalist in Dublin. 


\section{CORRECTION}

The News Feature 'Deep-sea dilemma' (Nature 571, 465-468; 2019) erroneously claimed that the 'gummy squirrel' sea cucumber Psychropotes longicauda is not found outside the CCZ. In fact, this species is widespread in the deep sea. 